\title{
Management of cervical heterotopic pregnancy with inevitable miscarriage
}

\author{
Shyamala R.*, Saranya Srikumar, Radhamany K.
}

Department of Obstetrics and Gynecology, Amrita Institute of Medical Sciences, Kochi, Kerala, India

Received: 18 December 2018

Accepted: 11 January 2019

\section{*Correspondence:}

Dr. Shyamala R.,

E-mail: shyamalaramesh516@gmail.com

Copyright: () the author(s), publisher and licensee Medip Academy. This is an open-access article distributed under the terms of the Creative Commons Attribution Non-Commercial License, which permits unrestricted non-commercial use, distribution, and reproduction in any medium, provided the original work is properly cited.

\begin{abstract}
The objective is to report a case of successful treatment of heterotopic cervical pregnancy resulting from IVF-ICSI conception. Case report from Amrita Institute of Medical sciences: a tertiary care referral hospital. A 47-year-old Primigravida, diagnosed with heterotopic cervical pregnancy at 6 weeks of gestation, presented with significant first trimester vaginal bleeding. Under IV sedation, Transvaginal ligation of descending cervical branches of the uterine arteries arrested the bleeding. The cervical pregnancy was successfully aborted with minimal bleeding and the intrauterine pregnancy was successfully maintained till 32 weeks, after which she required emergency preterm LSCS in view of Severe preeclampsia superimposed on chronic hypertension a non-reassuring non-stress test (NST). The intervention applied maybe used in treatment of heterotopic cervical pregnancy in a low resource setting to control the bleeding.
\end{abstract}

Keywords: Cervical pregnancy, Chronic hypertension, Heterotopic pregnancy, Inevitable abortion, Non-stress test, Preeclampsia, Preterm LSCS

\section{INTRODUCTION}

Heterotopic pregnancy is defined as presence of Intrauterine pregnancy (IUP) coexisting with an ectopic pregnancy. It is a rare entity with an incidence of $1 / 30,000$ in natural conceptions and $1 / 100$ to $1 / 3,600$ in ART conceptions. ${ }^{1,2}$ Cervical heterotopic pregnancy is the least common site of the Heterotopic pregnancy, the most common being tubal heterotopic pregnancy. The advances in transvaginal sonography has enabled early recognition of this entity. Standard guidelines for management of these pregnancies are yet to be laid due to its rarity. A total of 57 cases has been reported with only 3 case reports from India till date. Each case report in the literature has been approached individually based on resource availability, patient preference and physician's experience. In the past, diagnosis was often delayed, resulting in life-threatening haemorrhages at presentation, even leading to emergency hysterectomy. Termination of the entire pregnancy was therefore recommended as soon as possible to reduce the risk of cervical haemorrhage with possible maternal life-threatening complications. At present, more intensive gynaecologic care and extensive use of obstetric ultrasound has moved the timing of diagnosis of ectopic pregnancy to the early weeks of the first trimester.

Authors report a case of Heterotopic cervical pregnancy which presented as a case of Inevitable miscarriage with significant first trimester bleeding. A contemporary surgical approach was individualised for our patient in view of saving the Intrauterine pregnancy and to minimise the blood loss. She underwent transvaginal ligation of the descending branch of uterine arteries to prevent life threatening cervical haemorrhage. She was on regular follow up since then with no further episodes 
of bleeding during pregnancy. She delivered a healthy preterm live male baby by an uncomplicated lower segment emergency caesarean section in view of nonreassuring CTG and a severe pre-eclamptic state.

\section{CASE REPORT}

A 47-year-old ART treated Elderly primi-gravida was referred from an Infertility clinic as a suspected case of heterotopic cervical pregnancy at 6 weeks 1 day with history of vaginal bleeding of 1-day duration. She was married for 3 years. She was a pre-gestational diabetic on insulin and chronic hypertensive on regular antihypertensive medications. History of both male and female factor infertility noted. Multiple failed attempts of ovulation inductions, 3 failed Intrauterine inseminations and 1 failed IVF. Hence, she underwent ICSI conception with own gametes and 3 embryos transferred in blastocyst stage on Day 5 (17/2/2018). Pregnancy confirmed by Beta HCG on Day 14 (2/3/2018). She was on luteal phase supports with vaginal Progesterone. Early pregnancy scan done in IVF clinic (outside) on Day 25 (13/3/2018) showed two gestational sacs: one intrauterine and another cervical sac: possibility of a CHP. She was advised to review after a week to confirm the diagnosis. Three days later she had vaginal bleeding with which she was referred to our emergency room at 6 weeks 1 day $(16 / 3 / 2018)$.

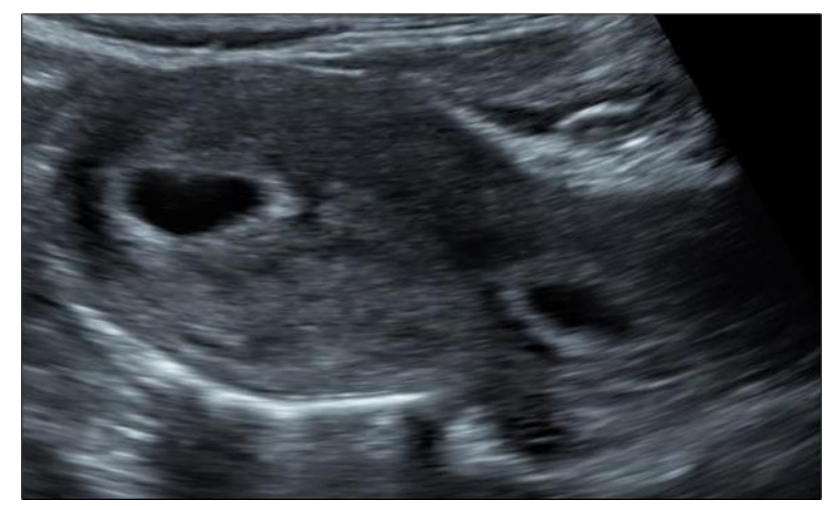

Figure 1: Trans-abdominal image.

On examination, she was hemodynamically stable, obese and short statured woman. On per speculum examination, cervix appeared ballooned out with a trickle of blood from the external os. Immediate transabdominal and transvaginal sonography showed a live intrauterine embryo with $\mathrm{CRL}=6.2 \mathrm{~mm} \quad(\mathrm{HR}=122 \mathrm{bpm})$, cervical embryo with $\mathrm{CRL}=2.6 \mathrm{~mm}(\mathrm{HR}=106 \mathrm{bpm}$ ) (Figure 1 and 2). Transvaginal color Doppler scan was performed to demonstrate peri trophoblastic flow in the cervical sac. A confirmed diagnosis of cervical heterotopic pregnancy (CHP) with a live intrauterine sac and a live cervical sac was made. In view of her high-risk factors like advanced maternal age, multiple failed attempts for pregnancy, diabetes and hypertensive status, she was counselled for surgical method of management so as to arrest the bleeding and save the intrauterine pregnancy.

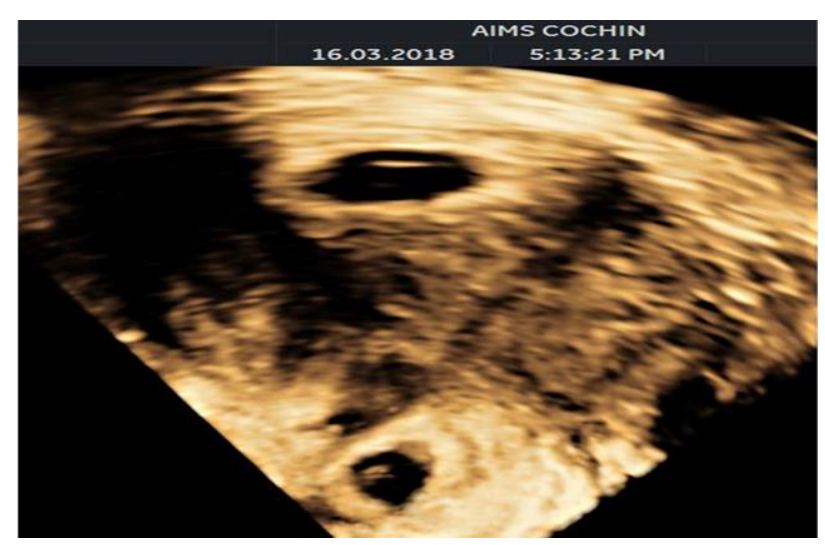

Figure 2: Transvaginal image.

She was explained regarding the consequences of severe hemorrhage with loss of Intrauterine pregnancy as well as need for hysterectomy in case of uncontrolled bleeding and if untreated. Hence after a high-risk informed consent and arrangements for blood and blood products, patient was positioned in lithotomy position. After painting and draping, vaginal walls retracted with speculum. Cervix visualised. Active bleeding noted from the partly dilated external os. Products of cervical sac seen extruding through the os, making the diagnosis as inevitable miscarriage. Transvaginal ligation of descending cervical branches of uterine arteries done using 1-0 chromic catgut and waited for the products of cervical sac to expel completely. Bleeding reduced significantly after few minutes and surgical field was clear. Post procedure HR documented in the intrauterine sac. Cervical sac appeared collapsed and small. She was catheterised for 24 hours and given bed rest for 24 hours. Parenteral antibiotic cover with 2nd generation Cephalosporin given. Bleeding subsided in 3 days with passage of clots on Day 2. She was discharged on $4^{\text {th }}$ day. She was reviewed at 8 weeks 3 days. TVS scan done showed a single live intrauterine gestation corresponding to 9 weeks $(C R L=23 \mathrm{~mm}) .1 .9 \mathrm{x}$ $1.4 \mathrm{cms}$ hypoechoic area suggestive of an organised clot noted in the cervical canal, cervical length- $3.3 \mathrm{~cm}$.

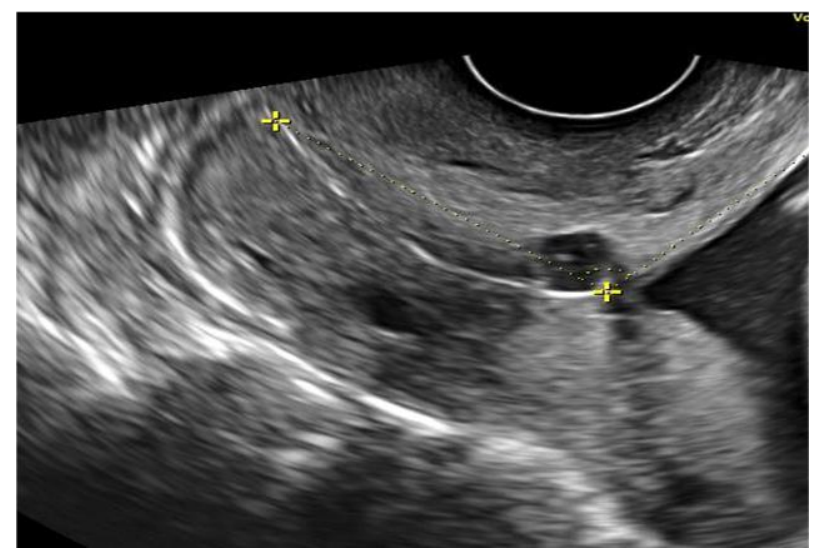

Figure 3: Anomaly scan-cervix.

Cervix was reassessed at the time of NT scan and anomaly scan at 11 weeks 6 days and 19 weeks 3 days of 
gestation, no hypoechoic area or abnormal vascularity noted at the cervix and cervical length measured $3.4 \mathrm{cms}$ (Figure 3).

Rest of the antenatal period was uneventful with no episodes of vaginal bleeding. At 32 weeks, she was admitted in view of elevated Blood pressure readings and diagnosed as chronic hypertensive with super imposed severe pre-eclampsia. Non-stress test done (NST) for fetal wellbeing on 32 weeks 4 days showed a nonreassuring pattern with persistent fetal bradycardia. Hence, she underwent Emergency Preterm LSCS on the same day and delivered a live male baby of birth weight $1.39 \mathrm{~kg}$. Intraoperatively cervix appeared normal. Baby was discharged from NICU after 30 days and presently doing well.

\section{DISCUSSION}

Incidence of heterotopic pregnancies is on rise, secondary to assisted reproductive technologies (ART). Heterotopic pregnancies are three times more common in ART conceptions than spontaneous ones. However, the exact mechanism predisposing to this entity is still unknown. Certain studies hypothesize that the presence of sticky cervical mucus at the time of introducing the plunger during embryo transfer, results in the embryos adhering to the cervix. Hence some prefer removing the cervical mucus selectively as a preventive measure to try and avoid cervical pregnancy. ${ }^{3}$ A previous cervical/uterine instrumentation or manipulation also predisposes to this entity. Management of cervical heterotopic pregnancy (CHP) brings forth more challenges as it can lead to uncontrolled catastrophic bleeding, which leaves the treating obstetrician no other choice than emergency hysterectomy. With advances in transvaginal sonography in terms of higher frequency imaging and color doppler, early diagnosis is made possible and it buys time to plan a safer and better management. On reviewing literature, a total of 57 cases have been reported till date.

Owing to the severity of consequences, CHP can be managed by termination of the entire pregnancy or selective reduction of cervical sac by medical/ surgical/ combined methods. With advent of interventional radiology by means of embolization techniques, life threatening hemorrhages can be prevented. Medical methods for selective reduction of cervical pregnancy reported in literature includes aspiration of the cervical sac with or without intraembryonic potassium chloride (KCL) injection/ intra amniotic methotrexate (MTX)/ hyperosmolar glucose injection. Surgical methods of selective reduction reported in literature include curettage /forceps extraction/suction or digital evacuation/ hysteroscopic resection/laser ablation with or without Cerclage/ Foleys inflation tamponade.

As our patient presented with significant first trimester bleeding, our treatment goals remained on arresting the bleeding without harm to the intrauterine pregnancy and preserving fertility. So, in present case, authors proceeded with surgical method of ligating the descending cervical branch of uterine arteries. Almost majority of the patients in the literature, were diagnosed as CHP at the onset of vaginal bleeding. Those symptomatic cases with bleeding per vaginum managed medically did not have a good prognosis and those managed with surgical methods had a better prognosis. Hence the symptomatology also is one of the criteria to decide management options. Hafner et al, described Tamponade with intracervical Foleys balloon inflation and cervical sutures applied at the external os for stabilizing the Foleys followed by ligation of descending cervical branches of uterine arteries. ${ }^{4}$ Later on, Systemic MTX was given for termination of the entire pregnancy (patients choice).

Tsakas et al, described successful treatment of CHP by suction aspiration of the cervical sac followed by Foleys tamponade and Shirodkars cerclage..$^{5}$ Vasiliki et al, followed similar principle of Foley's tamponade and cerclage, after removal of the cervical sac by ring forceps extraction. ${ }^{6}$ Faschingbauer et al, applied suction curettage with Shirodkar cerclage. ${ }^{7}$ In all these cases, intrauterine pregnancy progressed to term and had favorable outcome. In present case authors did not resort to tamponade as the cervical sac was in the process of expulsion at the time of procedure. Immediate cerclage was also planned if the bleeding was not arrested. But deferred as hemostasis was attained after ligation. It was scheduled for a later date, in case of cervical insufficiency. However, it was not done, as cervical imaging in later part of pregnancy, was within normal limits. Though medical methods were associated with quite a number of adverse outcomes, they are the first line of choice if the patient is asymptomatic and gestational age at diagnosis is earlier. Ujvari et al, had concluded that if the gestational age was less than 6 weeks, aspiration was safer and after 6 weeks KCL injection is better. ${ }^{8}$

Sijanovic et al, described that Intra-amniotic MTX can cause selective feticide and necrosis of trophoblastic tissue, without much adverse effects. ${ }^{9}$ Chen et al, proceeded with Aspiration of cervical sac followed by KCL injection. ${ }^{10} \mathrm{~A}$ week later had significant bleeding was managed under Epidural anaesthesia by cervical stay suturing with absorbable sutures. Pregnancy progressed till term followed by an uncomplicated delivery.

In present case, authors did not opt for Aspiration, as handling the cervical tissue itself is more traumatic and leads to severe bleeding. However, absorbable sutures were applied to the descending cervical branches of uterine arteries to arrest bleeding effectively. As a result of this contemporary approach, authors managed to reduce bleeding almost completely.

\section{CONCLUSION}

Though appearing to be a complex entity, CHP must be diagnosed early, and it should be managed in a systemic 
manner, depending on the patient's symptoms at presentation and availability of resources. Early recognition is the keystone is planning the management. The possibility of massive antepartum haemorrhage, DIC, chorioamnionitis, preterm labour, in the latter half of gestation, despite well managed cervical pregnancy must also be addressed prior to any mode of intervention.

Funding: No funding sources

Conflict of interest: None declared

Ethical approval: Not required

\section{REFERENCES}

1. DeVoe RW, Pratt JH. Simultaneous intrauterine and extrauterine pregnancy. Am J Obstet Gynecol. 1948;56(6):1119-26.

2. Fernandez H, Gervaise A. Ectopic pregnancies after infertility treatment: modern diagnosis and therapeutic strategy. Human Reprod Update. 2004;10(6):503-13.

3. Craciunas L, Tsampras N, Fitzgerald C. Cervical mucus removal before embryo transfer in women undergoing in vitro fertilization/intracytoplasmic sperm injection: a systematic review and metaanalysis of randomized controlled trials. Fertil Steril. 2014;101(5):1302-7.

4. Hafner T, Ivkosic IE, Serman A, Bauman R, Ujevic B, Vujisic S, et al. Modification of conservative treatment of heterotopic cervical pregnancy by Foley catheter balloon fixation with cerclage sutures at the level of the external cervical os: a case report. J Med Case Reports. 2010;4(1):212.
5. Tsakos E, Tsagias N, Dafopoulos K. Suggested method for the management of heterotopic cervical pregnancy leading to term delivery of the intrauterine pregnancy: Case report and literature review. J Minimally Invasive Gynecol. 2015;22(5):896-901.

6. Moragianni VA, Hamar BD, McArdle C, Ryley DA. Management of a cervical heterotopic pregnancy presenting with first-trimester bleeding: case report and review of the literature. Fertil Steril. 2012;98(1):89-4.

7. Faschingbauer F, Mueller A, Voigt F, Beckmann MW, Goecke TW. Treatment of heterotopic cervical pregnancies. Fertil Steril. 2011;95(5):1787-e9.

8. Ujvari E, Krizsa F, Sebestyen A, Varbiro S, Paulin F. Successful management of intrauterine twin and concomitant cervical pregnancy: a case report. Fetal Diagnosis Therapy. 2006;21(2):181-4.

9. Sijanovic S, Vidosavljevic D, Sijanovic I. Methotrexate in local treatment of cervical heterotopic pregnancy with successful perinatal outcome: case report. J Obstet Gynaecol Res. 2011;37(9):1241-5.

10. Chen D, Kligman I, Rosenwaks Z. Heterotopic cervical pregnancy successfully treated with transvaginal ultrasound-guided aspiration and cervical-stay sutures. Fertil Steril. 2001;75(5):10303.

Cite this article as: Shyamala R, Srikumar S, Radhamany K. Management of cervical heterotopic pregnancy with inevitable miscarriage. Int J Reprod Contracept Obstet Gynecol 2019;8:779-82. 